\title{
Promoting Innovation and Entrepreneurship Education in Physics: The
} PIPELINE Network

\section{Dr. Crystal Bailey, American Physical Society}

Dr. Crystal Bailey is the Head of Career Programs at the American Physical Society (APS) in College Park, MD. Crystal works on several projects which are geared towards marketing physics and physics career information to high school students, undergraduates, graduate students and physics professionals. Some of her principle projects include the Physics InSight slideshow, career events and workshops at APS annual and division meetings, the APS Job Board and Job Fairs, APS Webinars, and maintaining resources on the APS Careers Website. As the principle investigator for the APS PIPELINE project, she also devotes significant amounts of time to promoting innovation and entrepreneurship education in physics.

Before coming to the APS, Dr. Bailey did research in nuclear physics at Indiana University, Bloomington in the area of few-body systems. In 2008 she received the Konopinski Award for Outstanding Graduate Teaching from the IU Physics Department. She graduated with her PhD from IU in 2009. 


\title{
Promoting Innovation and Entrepreneurship Education in Physics: The PIPELINE Network \\ Crystal Bailey \\ American Physical Society \\ College Park, MD 20740
}

\begin{abstract}
Motivation
During the past 30 years, there have been ongoing concerns about the ability of the United States to compete in the global economy. The number and preparedness of STEM graduates is not meeting the current or anticipated demands of industry, technology and the broader workforce [1]. Twenty percent of jobs require a "high level" of knowledge in STEM and many more require some proficiency in STEM fields [2]. In response, national efforts were launched to increase the number and diversity of students pursuing degrees and careers in STEM fields. Despite these efforts, poor retention of students in STEM majors such as physics at colleges and universities continues to be a challenge [3].
\end{abstract}

While the reasons for this attrition may vary by discipline, there is some evidence that departments which make students' future career preparation as a focal point of their experience attract and retain more majors than those which do not. In the early 90s the National Task Force for Undergraduate Physics did a study, Strategic Programs for Innovations in Undergraduate Physics (SPIN-UP) [4], to understand why some physics departments experienced growing enrollments in spite of an overall decline in physics enrollments nationwide. According to this study, physics programs which experienced the least decline in enrollments during this period engaged in, among other things, career-focused practices such as: extensive career mentoring (e.g. access to alumni working in a diversity of career paths, assistance with $\mathrm{CV}$ or resume writing, networking, etc.), flexible majors programs tailored to students' future career interests, dual-degree engineering programs, and engaged learning experiences like undergraduate research programs. This finding would imply that future career prospects are an important consideration for students when considering whether to choose or finish a major.

These effects are particularly dramatic when we consider women and students of color. A recent report from the AIP Statistical Research Center, states that fewer than 5\% of the total bachelor's degrees awarded in the physical sciences between 2003 and 2013 were to African American students, and that the number of bachelor's degrees awarded to African Americans in physics has not increased at all since 2003, in spite of an overall increase of 39\% across all physical science fields during the same timeframe [5]. Physics also consistently graduates the smallest percentage of female undergraduate majors granted than any of the other sciences (one-fifth of all bachelor's degrees awarded to women as of 2014) [6]. At the same time, studies on lower-income students and students of color have indicated that a physics curriculum which focuses on the students' future identity--including future career identity--improves the degree to which they identify with and participate in science. [7,8]. Other studies indicate that physics classes which incorporate intentional affirmation of student values, which can include desired career outcomes, dramatically impacts the performance of marginalized students, such as women and students of color $[9,10]$. Therefore, a physics discipline which regularly connects content with commercial applications and/or careers would be more readily perceived as a useful, employable field, and therefore capable of attracting a more diverse group of majors. 
Additionally, while STEM majors who do complete their studies may possess strong technical facility, they sometimes lack the skills to apply their knowledge in the context of business and product development fundamentally needed to succeed in the workplace- particularly physics graduates, who have access to fewer mentors and courses informed by private sector experience than graduates in other STEM areas. Statistical data on the employment of physics graduates indicates that most of them will eventually work outside of traditional academic positions, and many of them in STEM fields other than physics - mostly in engineering [11-13]. Yet there are very few experiences incorporated into the standard undergraduate physics degree which explicitly help to prepare students for those career eventualities.

A survey conducted at Kettering University on employers who oversaw five-semester work and thesis projects of applied physics students found that students demonstrated the highest competency in solving problems, analyzing and interpreting data, and using current techniques and tools; it also found that they may be less prepared in such areas as leadership skills, the ability to work on multidisciplinary teams, the ability to recognize the value of diverse relationships (e.g. customers, supervisors), familiarity with basic business concepts (e.g. cost benefit analysis, intellectual property), and communication skills--particularly in how to tailor communication to a specific audience [14]. Following the success of SPIN-UP, the American Association of Physics Teachers and the American Physical Society have launched the Joint Task Force on Undergraduate Physics Programs (J-TUPP), specifically tasked with developing recommendations and standards for undergraduate programs to prepare students for 21 st century careers. The resulting report, Phys21, contains key recommendations: incorporating more realworld skills into the curriculum, including applications of physics to commercial problems and products; diversifying the skill base in experimental and laboratory equipment, software, and modeling; incorporating of core workplace skills into the student experience [15].

These kinds of professional skills will become increasingly important to the 21st century employer, who is increasingly likely to own a smaller company producing highly specialized technologies. This work environment benefits from individuals who can navigate a complex system of relationships and are competent in a variety of roles within a company - and the challenges of teaching these skills aren't confined only to physics [16]. A movement which will bring scientists into the STEM workforce with the confidence and scientific and technical ability that physics graduates are already known for - plus a host of other skills that will help them integrate into future roles on interdisciplinary teams, as powerful innovators that can translate ideas into solutions to real world problems. These changes will not only positively impact physics as a discipline, but the entire STEM workforce (of which physics graduates comprise a sizable part).

Physics is also a discipline that studies the foundational principles of nature, and thus is intimately involved in every type of technology which forms the basis of products and services. Many of the world's most important new technologies (e.g. the transistor, the laser, and the fiber optic cable) have originated in the minds of physicists who are able to draw upon a deep understanding of the physical world to create new, out-of-the-box solutions which in turn led to these new technologies. By its very nature, physics research prepares physicists to be generalists - able to work in and with a wide range of technologies, envision and oversee complex projects, 
and take advantage of links between physicists and regional industries and businesses that are mutually beneficial and can be the impetus for new technologies and products. By focusing on preparing students for successful careers, without also teaching the skills, knowledge, and mindset to also be innovative and impactful scientists in the workforce, we are overlooking an opportunity to help physics students realize their full potential as agents of positive change in the world.

\section{Physics Innovation and}

Entrepreneurship Education (PIE): A

\section{Definition}

Clearly there are many facets to the career and technology focused experiences which physics departments could offer their students. Here we define the specific approaches pursued during the course of this project, which serve to define what is here meant by "physics innovation and entrepreneurship" (PIE) education:

- experiences which convey professional skills (such as leadership, written and oral communication skills, and the

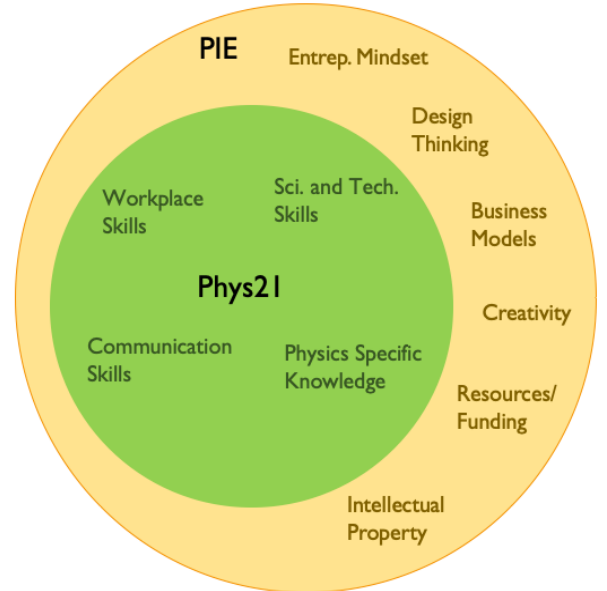

Fig. 1 - The scope of PIE related to the recommendations from Phys 21 ability to collaborate with interdisciplinary groups)

- experiences which develop a deep technological expertise, and the ability to use knowledge of physics principles to create innovative solutions to problems

- experiences which create familiarity with private sector concepts (e.g. intellectual property, business structures, commercialization, funding, etc.)

\section{The PIPELINE Network Project}

Despite the potential benefits of incorporating PIE elements into physics programs, there are many reasons departments are slow to adopt these strategies. These include a lack of awareness of actual employment outcomes for physics graduates (and therefore an understanding of the need for efforts which prepare students for non-academic career paths), a lack of institutional support for such efforts, an uncomfortable feeling of unfamiliarity with entrepreneurial concepts, and a lack of existing, tested PIE curricula that could be easily adapted to fit within their department's unique landscape of resources and constraints (including being integrated into existing physics coursework) [23].

In order to create a library of such curricula, deliberately varied in scope and resource needs, APS launched the NSF-funded PIPELINE Network program - a collaborative, three-year project which united the efforts of seven institutions (College of William and Mary, George Washington University, Loyola University Maryland, Rochester Institute of Technology, Worcester Polytechnic Institute, Wright State University, University of Colorado Denver) to develop and disseminate quality PIE materials and seed a nascent community of experienced PIE 
practitioners. This work was guided by educators who have already established successful innovation and entrepreneurship programs for physics students, e.g. the Scienceworks physics entrepreneurship bachelor's degree program at Carthage College, the physics entrepreneurship master's (PEP) program at Case Western University, and the engineering and applied physics programs at Kettering University. The group's work was also guided by an Industry Advisory Board comprised of physicists with extensive experience as entrepreneurs and in private sector companies.

Project activity was roughly organized along three central axes: developing and disseminating PIE curricular materials, increasing visibility of PIE among physics faculty and encouraging the formation of a cohesive community around PIE, and measuring faculty and student perceptions of physics related to innovation and entrepreneurship (and by extension, what are the key barriers to widespread adoption of these practices). $\mathrm{s}$

The PIPELINE team has also continued to leverage resources and experiences of other organizations focused on supporting innovation and entrepreneurship in STEM education, for example VentureWell (formerly known as the National Collegiate Inventors and Innovators' Alliance, NCIIA). Funded in part by the Lemelson and the Gates Foundations, VentureWell has a decades-long history working with educators spanning a wide variety of disciplines (including Engineering, Business, Art, Chemistry, and also Physics) on incorporating more innovation and entrepreneurship in their undergraduate programs. VentureWell has been a partner of the PIPELINE effort from the beginning, having co-sponsored a 2014 conference held at APS focused on innovation and entrepreneurship in physics. PIPELINE faculty have presented or will present both contributed and invited talks at two of VentureWell's annual Open conferences [17] $-[22]$.

\subsection{PIPELINE Network Outcomes}

The first outcome is that the PIPELINE team was successful in developing and cross-testing several sets of curricular materials. Examples of these materials include:

- A technical innovation and entrepreneurship course with an emphasis on physics based technology ventures, covering key business structures like idea generation, intellectual property, teamwork, business planning, patents and basic legal issues, physics applications (developed by Loyola University Maryland).

- Introductory physics modules incorporating technical feasibility, human desirability, and economic viability based on the Elon Musk Hyperloop concept and the human-powered irrigation pump created by KickStart International (developed at Loyola University Maryland) [24].

- A capstone course consisting of weekly sessions that teach students written and verbal communication skills, with an emphasis on accessibility of writing to an educated lay person with or without a STEM background (developed by George Washington University).

- Short-term, extra-curricular "pop-up" courses focused on teaching specific skills. Topics of these pop-up courses range from programming Arduinos to identifying the physics behind key modern technologies like Gorilla Glass (developed by Rochester Institute of Technology). 
- A module on teaching Agile Management methodology using a CubeSat scrum activity (developed at William and Mary).

All course materials, as well as instructor notes and webinar videos describing implementation methods, can be found on the APS PIPELINE site [25].

It should also be mentioned that many of these materials were developed through interdisciplinary collaboration between physics and other outside departments (e.g. business, engineering, biology). The goal of PIPELINE is to evolve the physics discipline such that its graduates emerge as successful, innovative, and impactful scientists; given that most physics graduates will either work on teams with graduates from many disciplines, or themselves be labeled as something other than "physicist," encouraging students to think across these boundaries is critical.

In addition to the curricular development, important research has been done into faculty and student attitudes toward PIE - and whether and how PIE should be considered part of "physics." These results have been published and presented at numerous physics education research conferences, and are summarized below. The PIPELINE Network has also established a monthly newsletter focusing on PIE topics, which is currently sent to an opted-in mailing list of over 250 physics faculty.

\section{Research Outcomes}

The research component of the PIPELINE program focused on understanding the perceived value of innovation and entrepreneurship education among physics faculty and students, and identifying attitudinal barriers to more widespread adoption of these practices. This research was done using surveys and semi-structured interviews with physics majors at the Rochester Institute of Technology, and then later through surveys sent to a broader cross-section of physics majors from a dozen institutions around the United States. The research discovered that while physics students perceived creativity, social impact, and design as being important to physics, they also believed they were least "learnable." Students also associated some key concepts aspects of innovation and entrepreneurship as being important to physics (e.g. technology, communication, creativity) but others (design, business) as being unimportant to physics and more closely related to other fields (e.g. business or engineering) [23].

This finding is significant for two reasons. The first is that design and business concepts (e.g. IP, funding sources, creating a value proposition, and project management) are routinely employed by even the most "pure" research academic in physics - even more so the vast majority of physicists who are employed in the private sector. The second is that it reveals a system of boundaries dividing the skills, knowledge, and mindset that serve all successful scientists in the workforce into discipline-specific regions that in the minds of students are not to be crossed. Again, as most STEM graduates will be collaborating in professional environments, confronting this habit of compartmentalization will be an important step in improving career development of students.

Because of the short duration of the project (three years), the relatively low number of participating institutions (seven) and the fact that much of the time was spent developing and testing new PIE curricula, it was not possible to measure any change to students attitudes 
stemming directly from having participated in the PIE implementations. The short time scale of the project also made it difficult to correlate career outcomes of students with participation of those students in PIE activities. However, the surveys that were developed could be a useful instrument for mapping such change for subsequent rounds of PIE adopters. Future plans include continuing to build the number of physics departments implementing PIE approaches, therefore increasing the number and scope of activities, making it possible for the assessment tools measure the effects of PIE adoption more clearly.

\section{Conclusion and Future Work}

The APS PIPELINE project has developed several new approaches to incorporating elements of entrepreneurship education into physics curricula. Until there is widespread adoption of these practices, it will be difficult to measure their direct effects on student perceptions of innovation and entrepreneurship in physics. However attitudinal barriers of physics students and faculty toward PIE adoption are understood, and can inform strategies to promote broader implementation. Future work will include continuing to build a community of practice so that more physics departments are actively developing, adapting, and using PIE curricula - as well as continuing to measure the effects of those implementations on faculty and student attitudes towards I\&E, and potentially how they impact recruitment and retention of majors.

It is worth noting that in developing an approach to teaching introductory physics that also incorporates innovation and entrepreneurship components, the PIPELINE project may also be of interest to engineering educators who are looking for an alternative to the standard intro physics courses that many engineering students are required to take. PIPELINE collaborators have sought, and will continue to actively seek opportunities for partnerships with individuals and organizations active in I\&E from other disciplines, in order to explore opportunities for further collaboration.

\section{References:}

[1] A. P. Carnevale, N. Smith, and M. Melton, "STEM: Science Technology Engineering Mathematics." Georgetown University Center for Workforce Development, October 2011. [2] J. Rothwell, “The Hidden STEM Economy.” Brookings Institute, June 2013.

[3] X. Chen, "STEM Attrition: College Students' Paths Into and Out of STEM Field," National Center for Education Statistics, Institute of Education Sciences, U.S. Department of Education, Washington, DC, NCES 2014-001, 2013.

[4] R. Hilborn, R. Howes, and K. Drane, "Strategic Programs for Innovations in Undergraduate Physics: Project Report," The American Association of Physics Teachers, College Park, MD, January 2003.

[5] L. Merner, "African American Participation among Bachelors in the Physical Sciences and Engineering." Focus On Report, American Institute of Physics Statistical Research Center, November 2015.

[6] Fraction of Bachelor's Degrees Earned by Women, by Major. College Park, MD: American Physical Society, 2015. Retrieved from http://www.aps.org/programs/education/statistics/womenmajors.cfm. 
[7] S. J. Basu, "How Students Design and Enact Physics Lessons: Five Immigrant Caribbean Youth and the Cultivation of Student Voice." Journal of Research in Science Teaching, vol. 45, no. 8, pp. $881-899,2008$.

[8] S. J. Basu, A. C. Barton, N. Clairmont, D. Locke, "Developing a framework for critical science agency through case study in a conceptual physics context." Cultural Studies of Science Education, vol. 4, no. 2, pp. 345 - 371, 2008.

[9] A. Miyake, L. E. Kost-Smith, N. D. Finkelstein, S.J. Pollock, G. L. Cohen, T. A. Ito, "Reducing the Gender Achievement Gap in College Science: A Classroom Study of Values Affirmation. Science, vol. 330, pp. 1234 - 1237, 2010.

[10] G. L. Cohen, J. Garcia, V. Purdie-Vaughns, N. Apfel, P. Brzustoski, "Recursive Processes in Self- Affirmation: Intervening to Close the Minority Achievement Gap.” Science, vol. 324, pp. $400-403,2009$.

[11] P. Mulvey, J. Pold, "Physics Bachelor's Initial Employment." Focus On Report, American Institute of Physics Statistical Research Center, April 2017.

[12] J. Pold, P. Mulvey, "Physics Masters One Year After Degree." Focus On Report, American Institute of Physics Statistical Research Center, December 2015.

[13] P. Mulvey, J. Pold, "Physics Doctorates Initial Employment." Focus On Report, American Institute of Physics Statistical Research Center, September 2019.

[14] B. Roughani, K. Svinarich. "ABET Self-Study Report for the Bachelor of Science in Engineering Physics”. Unpublished Self-Study, Kettering University, 2015.

[15] P. Heron, L. McNeil, et al. "Phys21: Preparing Physics Students for 21st Century Careers," Joint Task for for Undergraduate Physics Preparation, October 2016.

[16] R. K. Miller, "Why the Hard Science of Engineering is No Longer Enough to Meet the 21st Century Challenges (white paper)." Needham, MA: Olin College of Engineering. Retrieved from http://www.olin.edu/sites/default/files/rebalancing_engineering_education_may_15.pdf

[17] D. Arion, "Joint Task Force on Undergraduate Physics Programs (J-TUPP)," Presented at Open 2017, Washington, D.C., March 2017.

[18] C. Bailey, "Innovation and Entrepreneurship in Physics," Presented at Open 2017, Wshington, D.C., March 2017.

[19] R. Tagg, "Nonlinear PIE: Exploring Physics, Innovation, and Entrepreneurship (PIE) through Applications of Nonlinear Dynamics," Presented at Open 2017, Washington, D.C., March 2017.

[20] B. Roughani, "Bridging Scientific Thinking with Innovation and Entrepreneurial Mindset," Presented at Open 2017, Washington, D.C., March 2017.

[21] W. Deconinck, "Innovation and Entrepreneurship at a Liberal Arts University," Presented at Open 2017, Washington D.C., March 2017.

[22] C. Bailey, W. Deconinck, J. Gardiner, A. Newman, "Enabling Equity and Inclusion through Interdisciplinary Innovation," Planned Session at Open 2020, Salt Lake City, UT, March 2020. [23] A. Leak, C. Cammarota, B. Zwickl, "Physics students' perceptions about seven aspects of innovation and entrepreneurship," presented at Physics Education Research Conference (PERC) 2018, Washington D.C., July 2018.

[24] B. Roughani, R. S. Jones, A. M. Ernst, "Physics Innovation and Entrepreneurship (PIE) Introduced into the First-year Physics Course," 2019 ASEE Annual Conference \& Exposition Proceedings. 
[25] American Physical Society, “APS PIPELINE Network,” aps.org.

https://www.aps.org/programs/education/innovation/pipeline/index.cfm, , (accessed Feb. 3, 2019). 